\title{
NUEVAS APROXIMACIONES FILOSÓFICAS DE LA OBRA DE ANDRÉS EL CAPELLÁN
}

Cuando aún me encontraba trabajando en mi tesis doctoral, en donde intenté mostrar cómo el amor descrito en De Amore se presenta como un juego entre varones y mujeres nobles y plebeyos que al igual que otros juegos y diversiones como el ajedrez, los dados, la caza y los torneos ocupaban gran parte del tiempo libre de una nueva sociedad naciente hacia finales del siglo XII, el entusiasta Dr. Emiliano Aldegani me propuso realizar un número especial acerca de Andrés el Capellán en la prestigiosa revista de filosofía y ciencias Prometeica.

Ahora bien, las interpretaciones hegemónicas de De amore, que se han consolidado desde finales del siglo XIX, han sido llevadas a cabo por profesionales de la literatura que han visto en la obra del Capellán, o bien una codificación del amor cortesano, o bien algún tipo de ironía explicativa de la aparente contradicción entre los dos primeros libros en favor del amor mundano y el tercero en condena del mismo. Sin embargo, a poco de iniciar el milenio, D. A. Monson ha señalado, en su obra Andreas Capellanus, Scholasticism, and the Courtly Tradition (2005), la importancia de la influencia del contexto filosófico en la producción de la obra del Capellán. Andrés el Capellán es un dialéctico, un hombre formado en la tradición eclesiástica pero también en el arte de argumentar con silogismos que le permite mutatis mutandis generar un arte de seducción amorosa.

Ahora bien, ofrecer una interpretación filosófica de la obra del Capellán sigue siendo un desafío para los filósofos: ¿por qué el Capellán luego de enseñar el juego del amor, con bromas, humor y a veces con tono solemne, se inclina hacia el final de su obra en una condena del mismo? En mi tesis, propuse pensar en la identificación de Andrés el Capellán con la figura del aguafiestas (spielverderber) que he tomado de la teoría de juego desarrollada por Johan Huizinga en su ya clásica obra Homo ludens (1938). Sin embargo, con esto no he querido cerrar el debate sino proponer un marco lúdico filosófico para comprender una obra medieval que se desarrolla en un contexto donde el debate filosófico está en primer plano.

En este sentido, quisiera aprovechar esta editorial para agradecer de manera muy especial a todas las personas que participan en el número presente, todas ellas contribuyen a generar nuevos debates y se han mostrado interesados en poner en valor la figura del Capellán, a veces, pensándolo en relación con otros filósofos y pensadores que comparten tradiciones y abordan temas comunes como es el caso de los artículos de la Dr. Patrizia Di Patre, la Dr. Susana Gómez López, el Dr. Sergio Montalvo Mareca y la profesora Carolina Durán; en otras oportunidades se vuelve a indagar en la personalidad y el pensamiento del Capellán como es el caso del artículo y la entrevista en español realizada a D. Alfred Monson o también elaborando un marco teórico-lúdico más propio del siglo XXI para abordar obras medievales como es el caso del Dr. Juan Escourido. Finalmente, el Dr. José Enrique Ruiz-Domènec, quien en los años 1970 hiciera un promisorio trabajo sobre las relaciones entre el pensamiento de Andrés el Capellán y el juego del amor, nos ofrece una serie de reflexiones acerca de los vaivenes intelectuales de aquellos años en las universidades europeas, en especial de París y Barcelona, donde una nueva forma de hacer historia estaba emergiendo de la mano de historiadores como Georges Duby.

Por último, no querría dejar de mencionar la importancia de contar con un número especial acerca de Andrés el Capellán en lengua española teniendo en cuenta la escasez de trabajos en esta lengua y en este 
sentido agradecer a todo el equipo de la revista Prometeica por confiar en el abordaje de este autor y de su obra, con lo cual esperamos que resulte ser un material valioso para futuros investigadores hispanohablantes que deseen introducirse en los laberintos lúdicos y amorosos de Andrés el Capellán.

Nicolás Martínez Sáez - Editor invitado

(Universidad Nacional de Mar del Plata; Universidad Nacional de La Plata)

e-mail:martinezsaeznicolas@gmail.com 